\title{
Synthesis of New Derivatives of Monoazaphenothiazine via Tandem Catalysis
}

Swande Peter Iorember ${ }^{1 *}$, Anoh Vitalis Aondoaver ${ }^{2}$ and Agbo Stephen Attah ${ }^{2}$.

1. Department of Basic Sciences, Akperan Orshi College of Agriculture, Yandev, Gboko, Nigeria.

2. Organic Chemistry Unit, Department of Chemistry, Faculty of Science, Benue State University, Makurdi, Nigeria.

\begin{abstract}
The synthesis of new linear monoazaphenothiazine and its substituted derivatives via nickel catalyzed amidation reaction is reported. This was achieved by the condensation of 2aminothiophenol and 2,3,5-trichloropyridine in aqueous basic medium to produce a new heterocyclic ring, 3-chloro-1-azaphenothiazine. Upon applying, Buchwald-Hartwig Cross coupling reaction, it leads to the syntheses of an array of new 3-amido derivatives which were obtained in good yields. The structures of the synthesized compounds were established based on their analytical and spectra data
\end{abstract}

Key words: Synthesis, monoazaphenothiazine, tandem-catalyst, amidation, amido-derivatives.

\section{Introduction}

Phenothiazine (6) is a tricyclic heterocycle consisting of two benzene rings fused to a thiazine ring (7). It is also known as dibenzothiazine or thiodiphenylamine ${ }^{1}$.

Thiazine is an organic compound consisting of a ring of four carbon, one nitrogen and one sulphur atoms. Phenothiazine is a greenish-yellow crystalline compound soluble in acetic acid, benzene and ether. It belongs to an important class of heterocyclic compound known for their pharmaceutical properties and is the active ingredient in sedatives, tranquilizers, antituberculotics as well as antibacterial and fungi ${ }^{2}$. Research into phenothiazine and its derivatives has remained unabated. Owing to the wide range of application of this class of compounds as drugs , pesticides, dyes, industrial antioxidant, thermal stabilizers etc, necessitates this research. Phenothiazine is the parent compound of the large number of medicinal compounds and has been the subject of intensive study in industries and universities . 
Varriation in the structure of phenothiazine has resulted in the synthesis of its linear and nonlinear derivatives because substitution pattern in phenothiazine ring gives rise to distinguishable characteristics in their biological activities ${ }^{3}$. The linear phenothiazines are those whose sructures are in striaght chain ${ }^{4}$. The pharmacological activities of phenothiazine have been artributed to the basic nitrogen of the ring which donates electrons to the biological receptors by a charge transfer mechanism ${ }^{5}$. This makes the synthesis of aza-analogues of phenothiazine of ultmost interest to chemists ${ }^{6}$. Derivatives of phenothiazine with annular nitrogen atoms (aza-analogues) were expected to be better drugs than those without annular nitrogen ${ }^{7}$. In support of this conclusion, prothipendyl (8) and isothipendyl (9) are better drugs than chlorpromazine(10) and promethazine (11) respectively ${ }^{8}$. These interesting results call for more attention in the study of aza-phenothiazine analogues. It is the interest in this class of compound that prompted the present synthesis of the 3 -amido derivatives of monoazaphenothiazine via Tandem catalysis ${ }^{10}$.

\section{Experimental}

All reactions were carried out under an atmosphere of oxygen unless otherwise noted. All solvents and reagents were purchased from Sigma-Zayo Chemicals in sure-seal bottles and were used as received. Melting points were determined on a Fisher-Johns apparatus. The FT-IR spectra were recorded using $\mathrm{KBr}$ discs on a Shimadzu model 8400S infrared spectrophotometer. The NMR spectra were recorded on a Bruker DRX 400 spectrophotometer in DMSO at 400 MHz and $100 \mathrm{MHz} 1 \mathrm{H}$ NMR and 13C NMR with tetramethylsilane as the internal standard. The new compounds were characterized by $1 \mathrm{H}$ NMR, $13 \mathrm{C}$ NMR, MS and HRMS. The structure of known compounds were further corroborated by comparing their 1H NMR, 13C NMR data and MS data with those of literature. All reagents were obtained from commercial suppliers and used without further purification. Silica Gel column chromatography was performed using Merck 7734 Silica Gel (60 - 230 Mesh) and Merck-made TLC plates.

\section{Synthesis of 3-Chloro-1-azaphenothiazine (3).}

$4.0 \mathrm{~g}$ of Potassium Hydroxide was dissolved in $50 \mathrm{~mL}$ of distilled water and $5.0 \mathrm{~g}$ of $2-$ aminothiophenol solution was added to it in a $250 \mathrm{~mL}$ round bottomed flask and warmed in a 
water bath for 2-3 minutes until the mixture homogenizes as noticed by a yellow colouration. In a separate beaker, $7.30 \mathrm{~g}$ of 2,3,5-trichloropyridine and $50 \mathrm{~mL}$ of toluene were mixed thoroughly. This solution was added in drops unto the mixture in the $250 \mathrm{~mL}$ flask for an interval of 10 minutes.

The resulting mixture in the $250 \mathrm{~mL}$ flask was refluxed on a heating mantle for $3 \mathrm{hrs}$ with constant stirring using magnetic stirrer. At the end of the reflux period, the mixture was poured into a beaker, diluted with water to the $500 \mathrm{~mL}$ mark, placed in a chip of ice and cooled for 10 hrs. The 3-chloro-1-azaphenothiazine was separated from the refluxed mixture in two processes after 10 hrs cooling from ice chips.

In one way, the cooled mixture was separated using separating funnel, since the residue was a brown oily substance floating on the surface of the mixture. The brown oily residue was obtained and dried to drive out the solvent inside it. The resulting crystalline solid was recrystallized in 5 $\mathrm{mL}$ of benzene to obtain 3-chloro-1-azaphenothiazine $\mathbf{1}$ as greenish-yellow glistering power with melting point in the range of $106-107^{\circ} \mathrm{C}$.

In another way, the cooled mixture was filtered on a filter paper and an orange coloured filtrate was obtained. The filtrate was left undisturbed for $3 \mathrm{hrs}$, and then crystallizes. The rate of crystallization was induced by centrifuging the filtrate to obtain the crystals. The mixture was filtered and crystals dried on a filter paper to obtain (7.2g, 76\% yield of ) 3-chloro-1azaphenothiazine 1 as greenish-yellow glistering flakes with melting point in the range of $106-$ $107^{\mathrm{o}} \mathrm{c}$.

The following $\mathrm{IR}(\mathrm{KBr})$ data was obtained. The assigned structure is in line with the spectra data. The absorption band at $3438 \mathrm{~cm}^{-1}$ is due to (N-H stret), $3049 \mathrm{~cm}^{-1}(\mathrm{Ar}-\mathrm{C}-\mathrm{H}), 1615 \mathrm{~cm}^{-1}$ ( $\mathrm{C}=\mathrm{C}$ of aromatic rings), $1483-1417 \mathrm{~cm}^{-1}$ (C=N stret), $1350 \mathrm{~cm}^{-1}-1305 \mathrm{~cm}^{-1}$ (monosubstituted $\mathrm{Cl}$ ), $756 \mathrm{~cm}^{-}$ ${ }^{1}(\mathrm{C}-\mathrm{S}-\mathrm{C})$.

UV-Visible, $\lambda \max$ (ethanol), $307.2 \mathrm{~nm}(\log =2.490), 285 \mathrm{~nm}(2.464), 377 \mathrm{~nm}(2.556)$.

1HNMR(CDCl3), $87.05-6.30(6 \mathrm{H}, \mathrm{m}, \mathrm{Ar}-\mathrm{H}), 4.0(1 \mathrm{H}, \mathrm{s}, \mathrm{N}-\mathrm{H}) .13 \mathrm{CNMR}(\mathrm{CDCl} 3), \delta 147.4,146.9$, 
146.4, 135.8, 130.0, 128.6, 126.7, 126.1, 119.1, 118.8, 115.4 (11C,m,Ar-C). Analysis calculated for $\mathrm{C}_{11} \mathrm{H}_{7} \mathrm{~N}_{2} \mathrm{ClS}$; C,56.30, H,3.00, N,11.90, Cl,15.14, S,13.65. Analysis found: C,56.40, H,3.01, $\mathrm{N}, 11.78, \mathrm{Cl}, 15.20, \mathrm{~S}, 13.61$.

\section{General Procedure for the synthesis of compounds 16 - 19.}

An oven dried $250 \mathrm{~mL}$ two-necked flask which was equipped with a magnetic stir bar and fitted with a Teflon septum was charged with $0.3 \mathrm{~g}$ Nickel (II) chloride and $0.9 \mathrm{~g}$ Triphenyphosphine ligand. The vessel was evacuated and backfilled with nitrogen (this process was repeated thrice) and the $2 \mathrm{~mL}$ of ter-butanol and $1 \mathrm{~mL}$ of degassed water were added via syringe. After the addition of the degassed water, the solution was heated to $80^{\circ} \mathrm{C}$ for I minute. Thereafter, the solid reactants, $1.38 \mathrm{~g}, 0.01 \mathrm{~mol}$ of Potassium Trioxocarbonate (IV), compound $\mathbf{3}$ and the amide which was used for the amidation was added to the solution without extruction of air. The septum was replaced with a Teflon screw cap. The set up was then stirred at $110^{\circ} \mathrm{C}$ for four $4 \mathrm{~h}$ under a Nitrogen atmosphere until compound $\mathbf{3}$ had been completely consumed. The reaction mixture was then cooled to room temperature, diluted with ethyl acetate, washed with water and concentrated in vacuo. Purification of the crude product by silica gel using hexane/ethyl acetate as eluent gave the desired amido derivatives(16-19).

\section{3-Benzamido-1-azaphenothiazine (16)}

The assigned structure has absorption band at $3437 \mathrm{~cm}^{-1}$ in the infra red spectra which is due to $\mathrm{N}-\mathrm{H}$ bond, $1709 \mathrm{~cm}^{-1}$ is due to $\mathrm{C}=\mathrm{N}$ of pyridine moiety while the absorption band at $745 \mathrm{~cm}^{-1}$ is due to C-S-C. UV-Visible, $\lambda \max$ (ethanol) $237 \mathrm{~nm}, 261.8 \mathrm{~nm}(2.418), 307 \mathrm{~nm}(2.487)$, 409.8nm(2.613). 1HNMR (CDCl3), $7.79-6.30$ (9H,m,Ar-H), 4.0(2H,s,N-H). 13C-NMR (CDCl3), $147.4,146.7,141.9,137.5,136.0,134.1,130.0,129.3$, $126.1,119.1,118.8,118.5,115.1,112.7$

\section{3-Trifluoromethamido-1-azaphenothiazine (17)}

The absorption bands in the infra red at $3768-3074 \mathrm{~cm}-1$ is due to N-H bonding $1337 \mathrm{~cm}-158$ is due to $-\mathrm{NO} 2,742 \mathrm{~cm}-1$ is due to $\mathrm{C}-\mathrm{S}-\mathrm{C}$ and the absorption band at $1613-1506 \mathrm{~cm}-1$ is due to $\mathrm{C}=\mathrm{N}$ of pyridine moiety. UV-Visible $\lambda \max$ (ethanol), $212 \mathrm{~nm}(\log =2.326), 248.2 \mathrm{~nm}(2.395)$, 307nm(2.487), 360nm (2.556). 1HNMR (CDCl3), $\delta$ 7.79-6.30(10H,m,Ar-H), 4.0(2H,s,N-H). 13C-NMR (CDCl3), $\delta$ 149.2, 147.6, 147.1, 141.9, 137.5, 136.0, 134.1, 130.2,130.0, 126.1, 119.1, $118.8,115.4,113.6,112.7,110.2$. 


\section{3-Trichloromethanamido-1-azaphenothiazine (18)}

$\mathrm{IR}(\mathrm{KBr}), \mathrm{Vmax} 3438 \mathrm{~cm}-1$ (N-H stret), $3049 \mathrm{~cm}^{-1}$ (Ar-C-H), $1615 \mathrm{~cm}^{-1}$ ( $\mathrm{C}=\mathrm{C}$ of aromatic rings), $1483-1417 \mathrm{~cm}^{-1}$ (C=N stret), $1350 \mathrm{~cm}^{-1}-1305 \mathrm{~cm}^{-1}$ (monosubstituted $\mathrm{Cl}$ ), $756 \mathrm{~cm}^{-1}$ (C-S-C). UVVisible, $\lambda \max$ (ethanol), 309.2nm(log $=2.490), 291 \mathrm{~nm}(2.464), 360 \mathrm{~nm}(2.556)$.

1HNMR(CDCl3), $7.05-6.30(6 \mathrm{H}, \mathrm{m}, \mathrm{Ar}-\mathrm{H})$, 4.0(1H,s,N-H). 13CNMR(CDCl3), $147.4,146.9$, $146.4,135.8,130.0,128.6,126.7,126.1,119.1,118.8,115.4$.

Analysis calculated for C11H7N2ClS; C,56.30, H,3.00, N,11.90, Cl,15.14, S,13.65. Analysis found: C,56.40, H,3.01, N,11.78, Cl,15.20, S,13.61.

\section{3-(4-nitrobenzamido)-1-azaphenothiazine (19)}

The assigned structure is supported by spectral analysis. In the infra red spectra, the absorption band at $3476-3064 \mathrm{~cm}^{-1}$ is due to $\mathrm{N}-\mathrm{H}$ bonding, $1612 \mathrm{~cm}^{-1}$ is due to $\mathrm{C}=\mathrm{N}$ of pyridine, $1307 \mathrm{~cm}^{-1}$ is due to $-\mathrm{NO} 2$ while $747 \mathrm{~cm}-1$ is due to C-S-C. UV-Visible $\lambda \max$ (ethanol), 210.4nm(log $=2.323), 246 \mathrm{~nm}(2.391), 310 \mathrm{~nm}(2.491), 370.4 \mathrm{~nm}(2.569), 497.8 \mathrm{~nm}(2.70) 1 \mathrm{HNMR}$

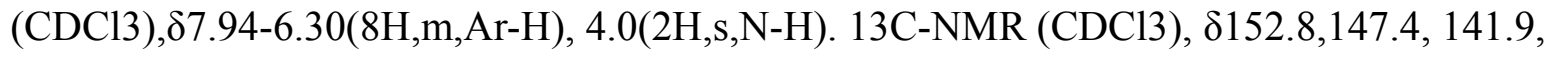
$138.4,137.5$, 136.0, 134.1, 130.0, 126.1,124.4, 119.1,118.8,116.0,115.4,112.7 
structure. 1HNMR(CDCl3), $87.05-6.30(6 \mathrm{H}, \mathrm{m}, \mathrm{Ar}-\mathrm{H}), 4.0(1 \mathrm{H}, \mathrm{s}, \mathrm{N}-\mathrm{H}) .13 \mathrm{CNMR}$

(CDCl3),8147.4,146.9,146.4,135.8,130.0,128.6,126.7,126.1,119. 1,118.8,115.4 (11C,m,Ar-C).

Elemental analysis data calculated for C11H7N2ClS; C,56.30, H,3.00, N,11.90, Cl,15.14, S,13.65. Analysis found: C,56.40, H,3.01, N,11.78, Cl,15.20, S,13.61. 
Table 1. Nickel-catalyzed amidation of 3-chloro-1-azaphenothiazine.

\section{CONCLUSION}

The amidation of monoazaphenothiazine derivatives via Nickel catalyzed Tandem reaction has been developed. The cross- coupling amido partners include benzamide, trifluoroacetamide, trichloroacetamide and nitrobenzamide which resulted in the synthesis of 3-benzamido-1azaphenthiazine, 3-trifluoroacetamido-1-azaphenothiazine, 3-trichloroacetamido-1azaphenothiazine and 3-nitrobenzamido- 1-azaphenothiazine respectively. Research on the biological and pharmacological activities of these synthesized amido derivatives of monoazaphenothiazine is ongoing.

\section{Acknowledgment}

The authors are grateful to Prof. U. C. Okoro for his advice, encouragement and contribution towards the success of this work.

\section{References}

1.Massie, S.P (1954): The Chemistry of Phenothiazine. Chem. Rev.54,791.

2. Smith,N.L (1951): Synthesis of Phenothiazine Derivatives. J.Org.Chem. 16, 415. 
3. Okoro, U.C (1990): Synthesis of new triaza and tetraaza analogues of Phenothiazine: Indian Journal of Chem.29B,117-120.

4.Okafor, C.O(1971): Studies in the Heterocyclic Series III. Chemistry of Azaphenothiazine Compound. Int. J. Sulphur Chem.6(3) 237-265.

5. Okafor, C.O(1981): Studies in the Heterocyclic Series XIX: Synthesis of 1,4diazaphenothiazine and its benzo derivatives. J. Heterocyclic Chem.; 18(2), 405-407.

6. Anoh, V.; Agbo, S.; Swande, P. Antimicrobial Evaluation of Some Monoazaphenoxazines Carboxamides: A Structural Activity Relationship (SAR). In Proceedings of the 18th Int. Electron. Conf. Synth. Org. Chem., 1-30 November 2014; Sciforum Electronic Conference Series, Vol. 18, 2017 , b008; doi:10.3390/ecsoc-18-b008

7. Agbo, S.A; Igbum, G.O; Anoh,A and Swande, P.I (2015): Synthesis and in Vitro Antimicrobial Activity of Some Novel Azaphenoxazine Carbonxamide Derivatives, IOSR J. of App. Chem. 8(4) 21-25.

8. Agbo, S, Anoh ,A, and Swande, P. (2017): Antifungal Activity of Some Monoazaphenoxazine Carboxamide Derivatives. Biological and Chemical Research, Science Signpost Pblishing 44-50.

9. Okafor, C.O; Steenberg, M.L and Buckley, .P(1976): Studies in the Heterocyclic Series XIII; New CNS-depresants derived from 1,9-Diazaphenothiazine and two isomeric Triazaphenothiazine ring system. Eur. J. Med. 3, 229-255.

10. Rama Rao Nadendla (2007): Principles of Organic Chemistry. Chem. Rev. 13, 78-86. 